\title{
Experimental model of distraction osteogenesis in edentulous rats
}

\author{
Maria Montserrat Pujadas Bigi(a) \\ Marianela Lewicki(a) \\ Angela Matilde Ubios ${ }^{(a)}$ \\ Patricia Monica Mandalunis(a)
}

(a) Department of Histology and Embryology, School of Dentistry, University of Buenos Aires (UBA), Argentina.

\section{Corresponding author:}

María Montserrat Pujadas Bigi

Department of Histology and Embryology

School of Dentistry - University of Buenos

Aires (UBA)

M.T. de Alvear 2142, $1^{\circ}$ "A"

CEP: C1122AAH

Ciudad Autonoma de Buenos Aires -

Argentina

E-mail:montsepujadas@gmail.com

Received for publication on Jan 05, 2011 Accepted for publication on Apr 28, 2011
Abstract: Distraction osteogenesis (DO) is a surgical technique producing bone lengthening by distraction of the fracture callus. Although a large number of experimental studies on the events associated with DO of craniofacial skeleton have been reported, the few employing rat mandibular bone DO used complicated designs and produced a small volume of newly formed bone. Thus, this study aims to present an original experimental model of mandibular DO in edentulous rats that produces a sufficient quantity and quality of intramembranous bone. Eight male Wistar rats, weighing $75 \mathrm{~g}$, underwent extraction of lower molars. With rats weighing $350 \mathrm{~g}$, right mandibular osteotomy was performed and the distraction device was placed. The distraction device was custom made using micro-implants, expansion screws, and acrylic resin. Study protocol: latency: 6 days, distraction: $1 / 4$ turn $(0.175 \mathrm{~mm})$ once a day during $6 \mathrm{~d}$, consolidation: $28 \mathrm{~d}$ after distraction phase, sacrifice. DO-treated and contralateral hemimandibles were dissected and compared macroscopically and using radiographic studies. Histological sections were obtained and stained with H\&E. A distraction gap filled with newly formed and mature bone tissue was obtained. This model of mandibular DO proved useful to obtain adequate quantity and quality of bone to study bone regeneration.

Descriptors: Osteogenesis; Bone Regeneration; Osteogenesis, Distraction; Bony Callus.

\section{Introduction}

Distraction osteogenesis is a surgical technique by which bone regeneration is induced between surgically osteotomized bone segments that undergo gradual distraction, resulting in bone lengthening. The soft tissues surrounding the distracted bone have also been found to regenerate. Codivilla was the first to explore DO, and in 1904 reported applying this technique for lengthening of the lower limbs. ${ }^{1}$ However, it was not until 1950 that this technique widespread through the works of Ilizarov. ${ }^{2,3}$ In 1992, Mc Carthy et al. were the first to perform mandibular DO in humans. ${ }^{4}$ As to the experimental models reported in Medline English literature, there are a number of DO models in endochondral long bones, such as rabbit, ${ }^{5} \mathrm{dog},{ }^{6}$ rat,${ }^{7}$ chicken, ${ }^{8}$ rat tibia and femur. ${ }^{9}$ However, extrapolation of results of experimental works on endochondral bone to the maxillae is limited, given that the latter are of different embryologic origin and are formed mainly through membranous ossification. In addition, 
their remodeling pattern and blood supply is different from that of endochondral long bones. Thus, the parameters used to evaluate DO in long bones may not be optimal to evaluate craniofacial DO. ${ }^{10}$ Although there are reports on experimental models in membranous bone of different animals, including dog, ${ }^{11}$ pig, ${ }^{12}$ rabbit mandibles, ${ }^{13-15}$ and sheep maxillae, ${ }^{16,17}$ comparison and interpretation of data is complex on account of the variations among studies regarding species, the protocol employed, and the anatomical site studied. ${ }^{18}$

Experimental models in rats present a series of advantages since the need to use larger animals is avoided, the cost of maintenance is lower, the experimental time points are shorter, and a larger number of animals can be employed. To date, experimental models of endochondral bone DO in rats have used devices designed to fit the tibia, ${ }^{6,7}$ and those reporting membranous bone DO have employed distraction devices designed to fit rat cranium ${ }^{19}$ or dentate mandible. ${ }^{18,20-26}$

\section{Rat mandible}

Mandibular bone is of ectomesenchymal origin and forms mainly through membranous ossification, with some portions of hyaline cartilage that will participate in secondary growth and which will later be replaced with bone formed by endochondral ossification. Thus, the mandible possesses distinctive features in different regions, which must be taken into account when selecting the site to apply a distraction osteogenesis device.

Different types of ossification processes occur in the mandible. It is therefore paramount to find the most suitable site to specifically evaluate membranous bone DO, which must be free of other tissues, such as hyaline cartilage, periodontal ligament, dentin, cementum, and so forth. The ideal sector to perform such evaluation is the alveolar ridge, where there are no secondary cartilages. However, the presence of molars could pose a problem since teeth and associated tissues encountered at the chosen site might render osteotomy and subsequent evaluation of healing somewhat difficult. Hence, the present model involved extraction of the mandibular molars.
Thus, the aim of the present study was to develop an original experimental design of mandibular DO in edentulous rats that would produce the sufficient quantity and quality of membranous bone to allow evaluating the events involved in the bone regeneration process that takes place during DO.

\section{Methodology}

Eight male Wistar rats weighing seventy-five grams were used. All procedures were reviewed and approved by the Ethics Committee of the School of Dentistry of the University of Buenos Aires, which follows the Guide for the Care and Use of Laboratory Animals (NRC 1996). Extraction of lower molars of both hemimandibles was performed under general anesthesia by intraperitoneal (IP) injection of ketamine $40 \mathrm{mg} / \mathrm{kg}$ (Ketamina 50, Holliday-Scott S.A., Beccar, Buenos Aires, Argentina) and xylazine 5 mg/kg (kensol König, Laboratorios König S.A., Avellaneda, Buenos Aires, Argentina) following the technique described by Guglielmotti and Cabrini. ${ }^{27}$ Subcutaneous antibiotic administration was performed postoperatively (benzatinic and procaine penicillin, $0.1 \mathrm{~mL} / \mathrm{kg}$, Dipenisol Retard, Bayer S.A., Buenos Aires, Argentina). The animals were housed in cages and fed a soft diet ad libitum for 1 week. Sixty days post-extraction, alveolar wound healing was complete and the rats had grown to an adequate size to undergo osteotomy and distraction.

\section{Osteotomy and distraction}

Under general anesthesia, right mandible osteotomy was performed when rats had grown to weigh $350 \mathrm{~g}$; the procedure finishes with the placement of a distraction device. After antisepsis and shaving the skin of the right sub-mandibular region, a 2 -cm long antero-posterior incision was made along the lower edge of the mandible using a blade scalpel. The skin and subcutaneous tissue were dissected to disclose the medial masseter-pterygoid sling, which was sectioned using the scalpel. Using a blunt spatula, both muscles were then detached to expose both the internal and external aspects of the mandibular body. On the external surface of the mandible, in the middle region corresponding to the mesial aspect of the lower first molar, there is 
an approximately $8-\mathrm{mm}$ long bony crest extending from the mesial aspect of the lower first molar to the gonial angle. Using a $0.5-\mathrm{mm}$ cylindrical bur at $300 \mathrm{rpm}$ (revolutions per minute) and under profuse irrigation with saline solution, the osteotomy site was marked on the middle region of the aforementioned bony crest, $4 \mathrm{~mm}$ from and perpendicular to the residual ridge. Using a cylindrical bur, a 1-mm diameter hole was drilled through two cortical layers of the mandible, six millimeters anteriorly and posteriorly to the marked site. A second hole was drilled behind the posterior perforation in order to increase anchorage in the region of the mandibular ramus. The Micro-implants for orthodontic traction (MIOTs) were screwed into the holes and osteotomy was performed using burs at low rotation speed and using a water cooling system. The distraction device was placed to test proper positioning and ensure it exerted no tension on the fracture ends, and was then removed. The wound was closed in layers and sutured using 5.0 nylon suture for deep layers and 3.0 nylon suture to close the skin. The distraction device was placed again and fixed with self-curing acrylic resin. The present device is an extra-oral distraction device.

\section{Distraction Device}

An acrylic lock was made on each side of a Mini Dentaurum $^{\circledR}$ expansion screw, to hold the MIOT

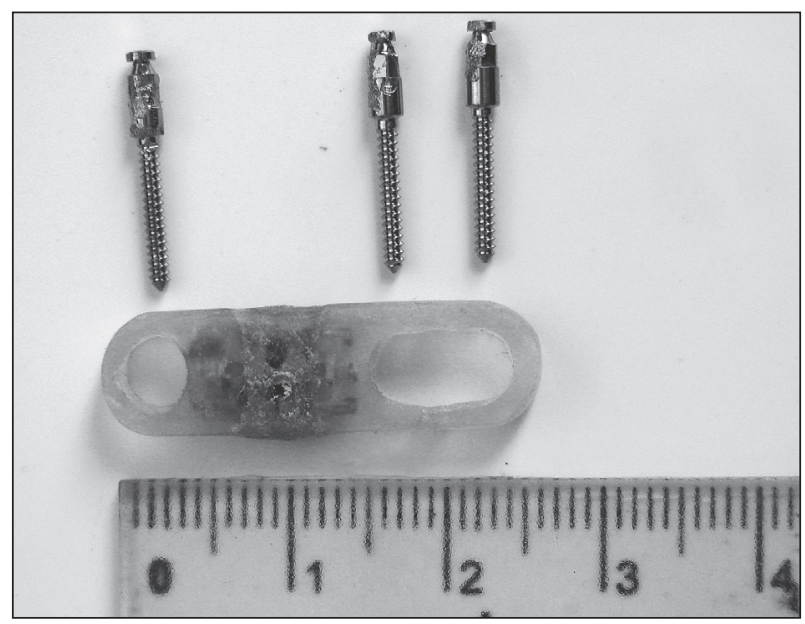

Figure 1 - Construction of the device. Distraction device made using $B \& W^{\circledR}$ micro-implants for orthodontic traction and a Mini Dentaurum ${ }^{\circledR}$ orthodontic expansion screw. when placing the device and fixing it inside the jaw. These acrylic locks were cut using burs and polishing sandpaper discs in order to obtain a device small enough to adapt to the size of the hemimandible of a 350 -g body weight rat (Figure 1).

\section{Proposed Study}

- Weaned male rats, $75 \mathrm{~g}$ b.w.: Tooth extraction

- On reaching 350 g b.w.: Osteotomy and distraction device placement

- Latency period: 6 days

- Active distraction consisted of a $1 / 4$ turn $(0.175 \mathrm{~mm})$ of the maxillary expansion screw once a day during 6 days

- Period of consolidation: 28 days after the active distraction phase. During this period the device is not activated and only functions as an external fixator

- Sacrifice

\section{Radiographic Techniques}

Radiographs were taken at the end of the experiment prior to and after removal of the distraction device, using periapical dental radiographic film and MTX 70 mV 8mA dental X-ray equipment (Dental San Justo, Buenos Aires, Argentina) at $70 \mathrm{Kv}$ and $0.8 \mathrm{sec}$ exposure time; the focus-to-film distance was $40 \mathrm{~cm}$. Radiographs were processed following standard protocols.

\section{Materials processing}

The animals were sedated with $0.5 \mathrm{mg} / \mathrm{kg}$ b.w. of acepromacine and then sacrificed by sodium thiopental (Pentotet $^{\circledR}$, Richmond Vet, Buenos Aires, Argentina) overdose. The heads were resected and fixed in $10 \%$ buffered formalin. X-rays were taken perpendicular to the occlusal plane of the mandible to confirm the position of the distraction device and the gap created throughout the experiment. The hemimandibles were dissected, the distraction device was carefully removed and the mandibles were radiographed horizontally and vertically to observe the distraction gap (Figure 2). The hemimandibles were decalcified in EDTA (ethylenediaminetetraacetic acid) at pH 7 and embedded in paraffin. Sixmicron thickness mesiodistal sections parallel to 


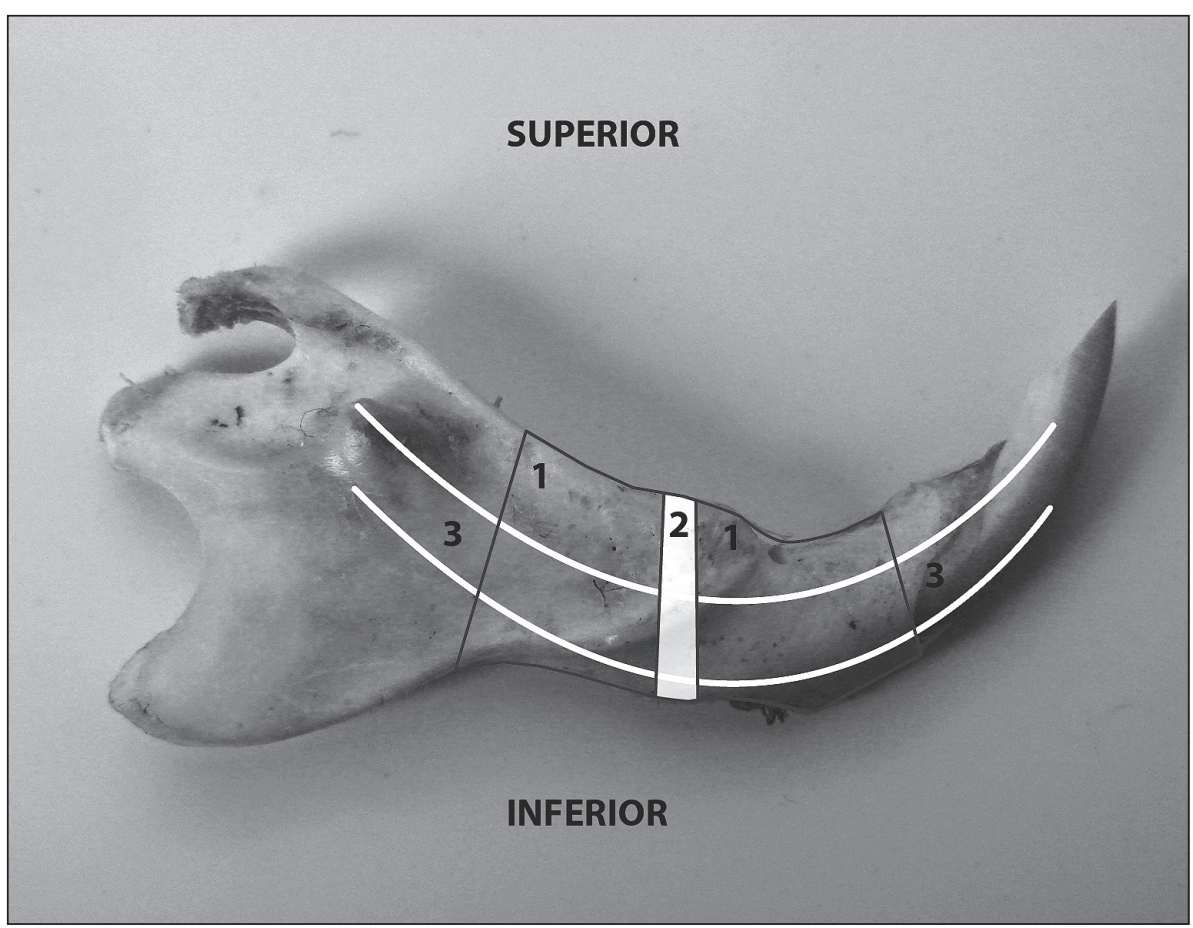

Figure 2 - photograph of the hemimandible of an edentulous rat weighing $350 \mathrm{~g}$ on which a diagram was drawn to show: (1) anterior and posterior regions of the residual ridge; (2) distraction gap; (3) lower incisor.

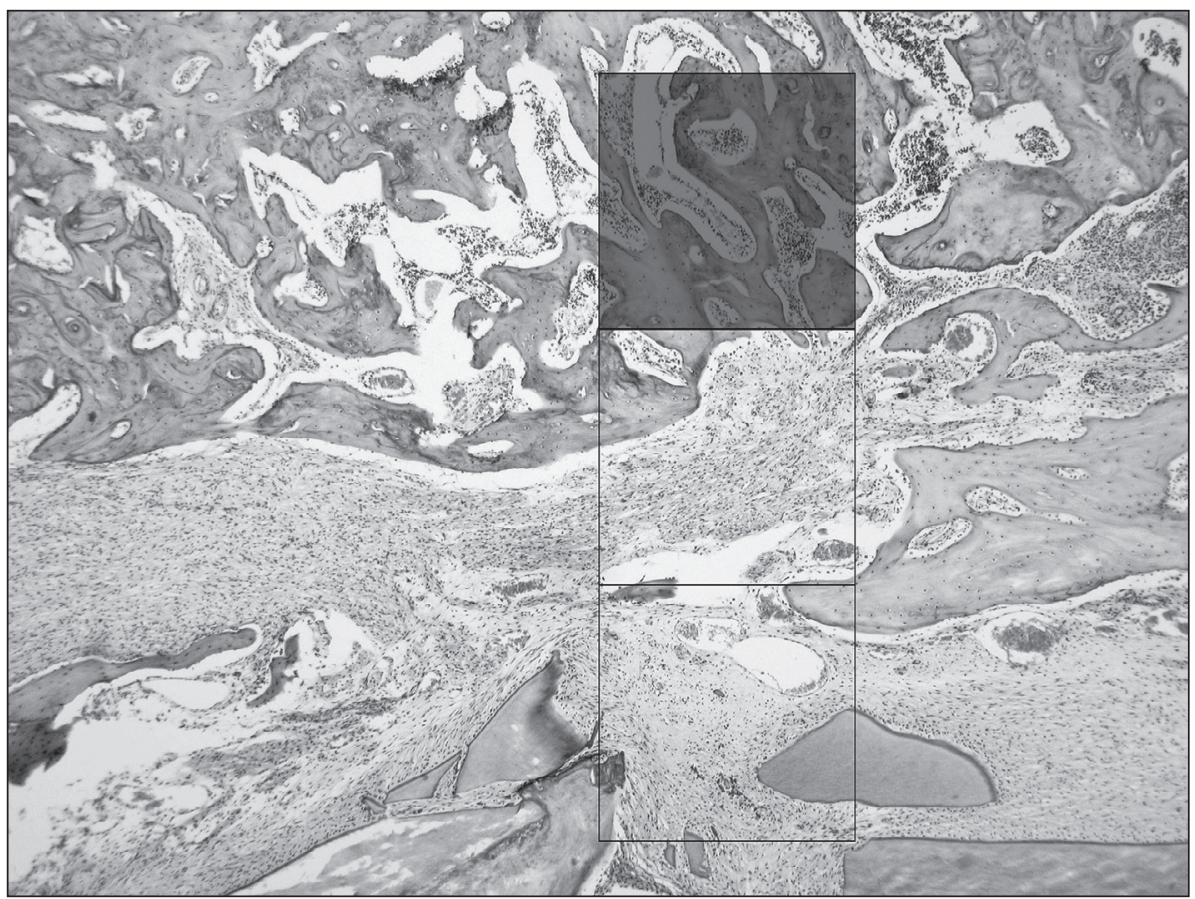

Figure 3 - histologic

microphotograph of a DOtreated rat showing the grid used to perform measurements of the bone gap. The lighter square shows the suggested site for obtaining comparable results. H-E. Magnification: 250×.

the residual ridge were obtained and stained with hematoxylin-eosin (H-E) following standard protocols. The sections were used to adjust the technique for measuring, determining and recording newly formed bone (Figure 3).

\section{Results}

\section{Edentulous left hemimandible of animals} not subjected to DO

Gross examination and radiographic study

Figure $4 \mathrm{a}$ shows the hemimandible of an animal 
of $350 \mathrm{~g}$ of body weight but subjected to molar extraction when weighing $75 \mathrm{~g}$; figure $4 \mathrm{~b}$ is the corresponding radiograph, evidencing that the residual ridge healed completely, was sufficient in quantity for this experimental design, and presented similar radiopacity to that of surrounding mature bone.

\section{Histologic Study}

As can be observed in Figure 5, following extrac-

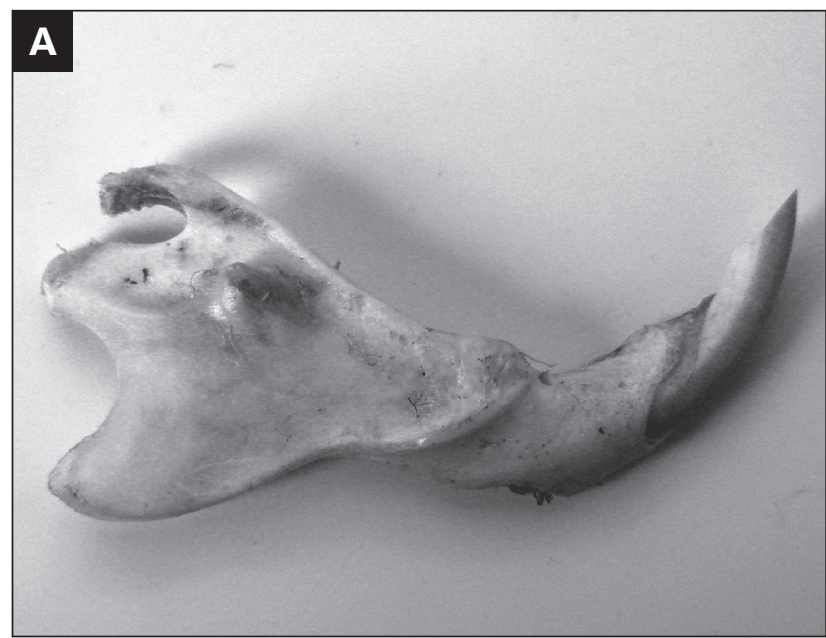

Figure 4 - (A) Edentulous hemimandible of a $350 \mathrm{~g}$ b.w. rat. after tooth extraction. tion of molars, healing resulted in the presence of mature bone tissue with a mineralized bone matrix exhibiting incremental lines that demonstrate the occurrence of both bone modeling and remodeling.

\section{Edentulous right hemimandible of animals subjected to distraction}

Gross Examination and radiographic study The distraction device used herein proved to be

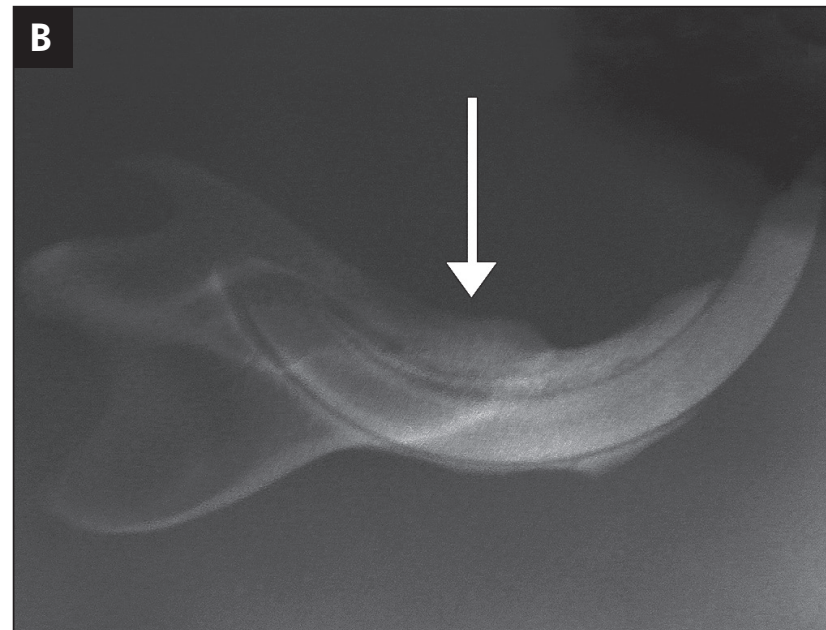

(B) Radiograph of (A). Note the residual ridge (arrow) 2 months

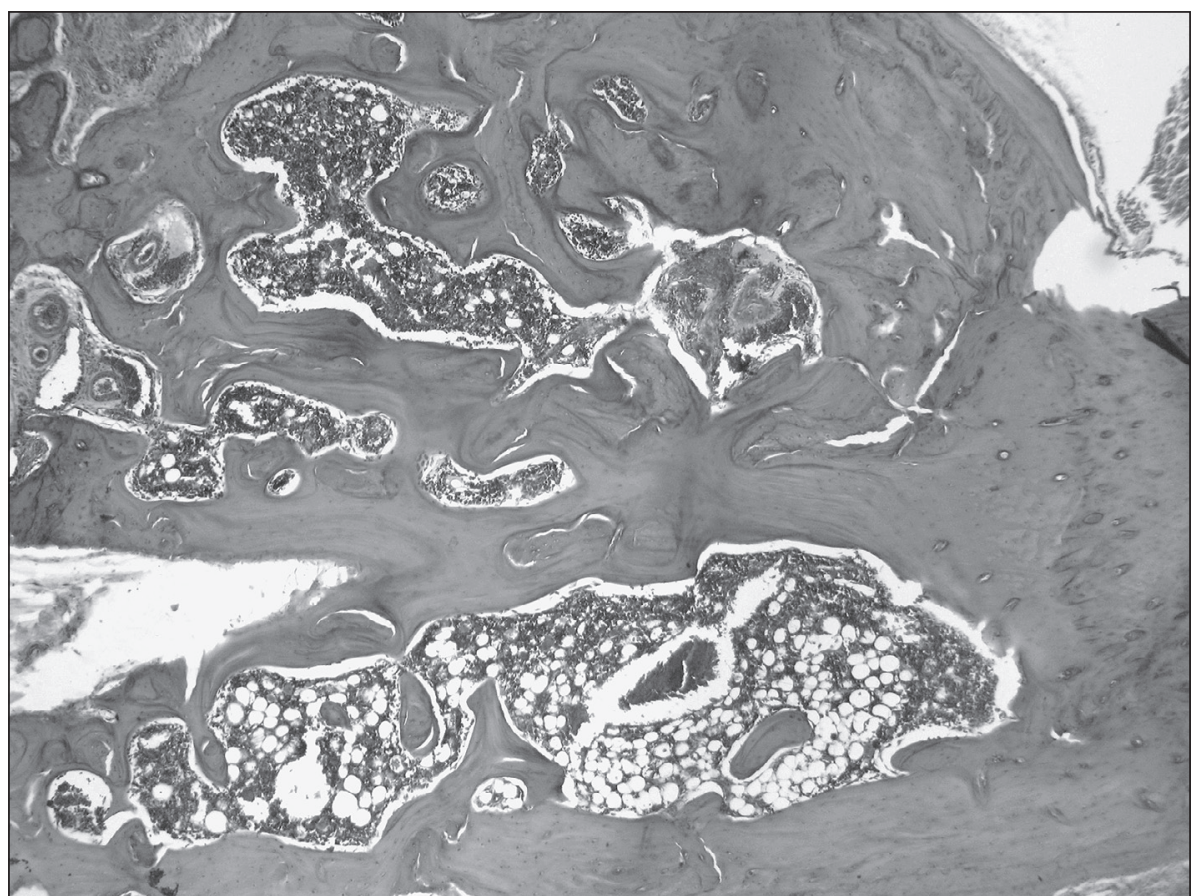

Figure 5 - Histological section of a residual ridge of a $350 \mathrm{~g} \mathrm{b.w.}$ evidencing that alveolar bone healing is complete. Note that the tooth sockets are filled with mature remodeled bone 60 days after tooth extraction. H-E. Magnification: $250 \times$. 
appropriate both as regards size and simplicity of design and placement and use during surgery. Radiographs taken prior to removing the distraction device allowed confirming the proper placement and position of the device (Figure 6a). Radiographs taken after removal of the device proved a useful guide to obtain adequately oriented histological sections (Figures $6 \mathrm{~b}$ and $6 \mathrm{c}$ ).

\section{Histologic Study}

Figure $6 \mathrm{~d}$ is a microphotograph of a histological section of an animal subjected to the osteotomy and distraction protocol; it shows the proper orientation
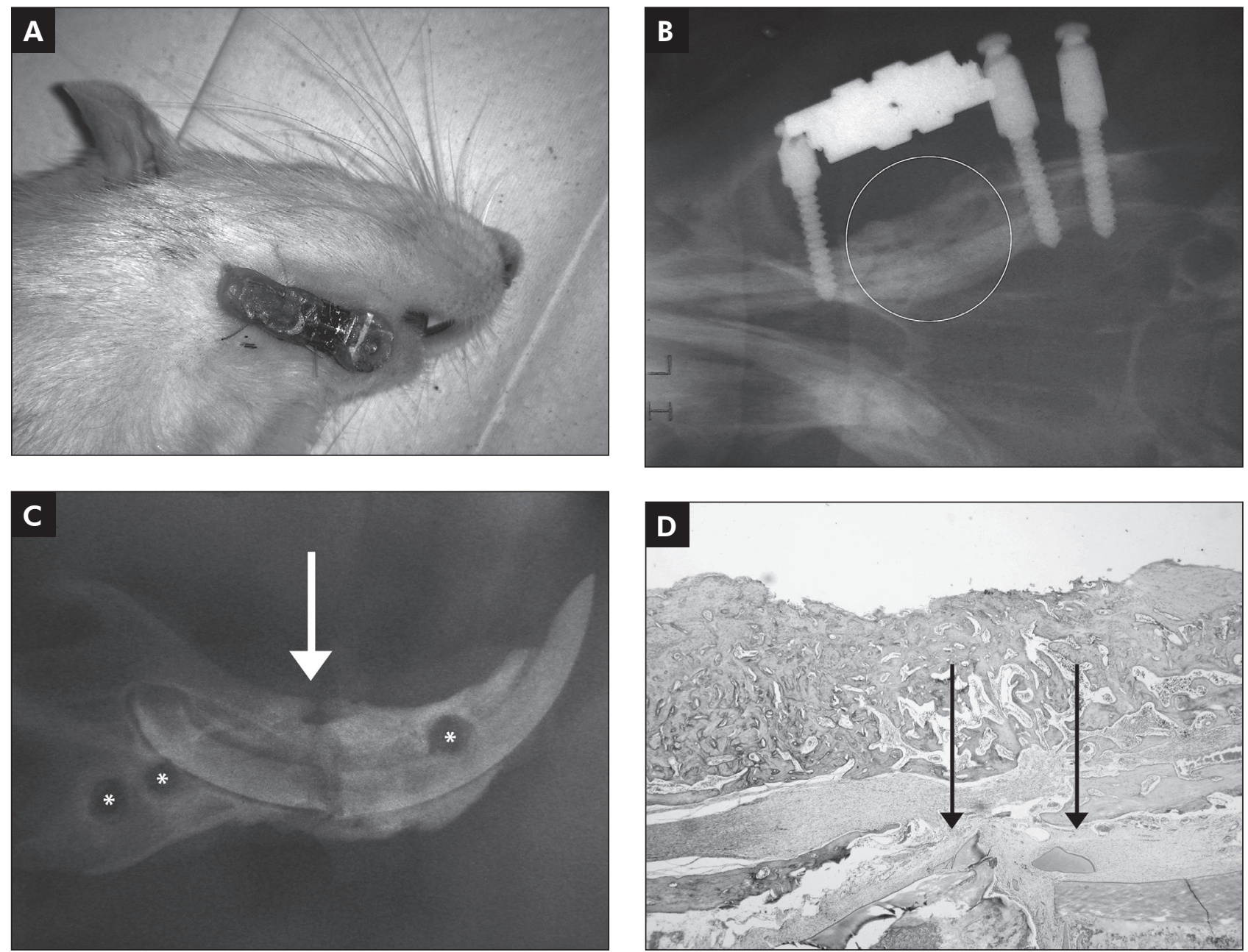

D

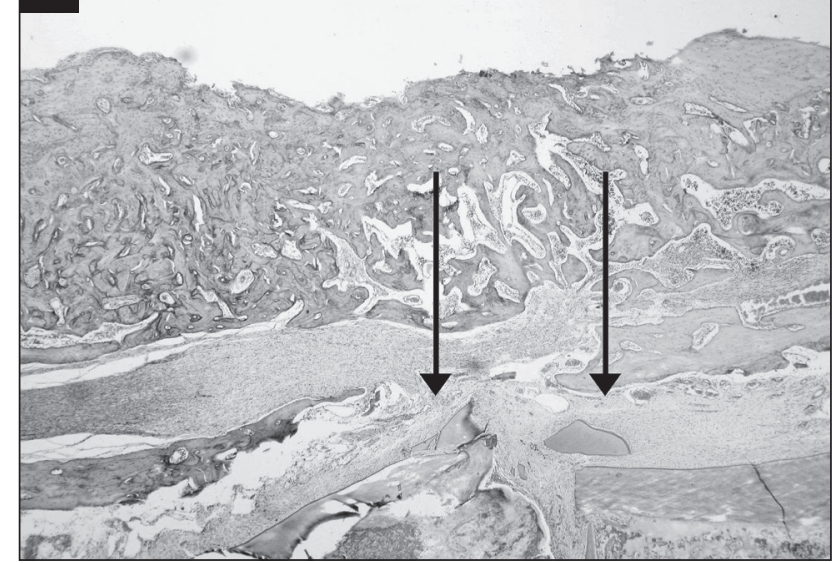

Figure 6 - (A) Distraction device placed in a rat. Photograph taken after the latency period. (B) X-ray of the head of a rat showing the distraction device in place. The beam is oriented vertically downward. The distraction gap can be seen in the circle. (C) Xray of a hemimandible after dissection and removal of distraction device. The gap (arrow) and the holes for MIOT placement can be seen $\left({ }^{*}\right)$. (D) Microphotograph of a histological section after completing the entire distraction osteogenesis protocol. Note that healing of the residual ridge bone is complete. The sectioned or fractured continuously erupting tooth filled with fibrous tissue (arrows) can be seen in the lower part of the image. H-E 500X. 
nous bone and avoiding the presence of teeth. This is particularly significant when attempting to study bone tissue specifically. Teeth comprise dentin, enamel, cementum, and the periodontal ligament, and their presence in the osteotomy site might interfere with the healing process and bias interpretation of results. Experimental models of mandibular DO in rats reported in the literature performed osteotomy between the first and second molar, ${ }^{20}$ between the second and third molar, ${ }^{26}$ and behind the three molars. ${ }^{28}$ In 2008, Ali et al. reported a histologic study on the cellular events that take place during DO in rats; the authors performed their study in basal mandibular bone on the grounds that it plays an important functional role. ${ }^{29}$ We chose to use residual ridge bone since, in addition to obtaining a greater volume of bone to work with, it is a functional bone with a higher remodeling rate than other types of bone. ${ }^{30}$ Other authors performed distraction in the mandibular ramus of the rat; ${ }^{18}$ it must be pointed out, however, that this is a very thin part of the mandible, making it difficult not only to perform osteotomy during surgery, place the distraction device, and later activate the device, but also to obtain properly oriented histological sections. Furthermore, because the secondary condylar and coronoid growth cartilages are located in the mandibular ramus, it presents two types of ossification: membranous ossification in some areas and endochondral ossification in the coronoid apophysis and mandibular condyle.

To date, there are no previous reports on mandibular DO in edentulous Wistar rats. The experi-

\section{References}

1. Codivilla A. The classic: on the means of lengthening in the lower limbs, the muscles and tissues which are shortened through deformity. Clin Orthop Relat Res. 2008 Dec;466(12):2903-9.

2. Ilizarov G. The tension-stress effect on the genesis and growth of tissues. Part I: the influence of stability of fixation and soft-tissue preservation. Clin Orthop Relat Res. 1989 Jan;(238):249-281.

3. Ilizarov G. Clinical application of the tension-stress effect for limb lengthening. Clin Orthop Relat Res. 1990 Jan;(250):826. mental post-tooth extraction time allowed for complete bone healing. By the time the rat had grown to weigh $350 \mathrm{~g}$, alveolar bone healing was complete and mandible size was adequate to place the distraction device. The microphotographs show that the quality and quantity of the newly formed bone was excellent. Thus, the DO model described herein would allow drawing more reliable conclusions regarding the regeneration process induced by distraction osteogenesis. The distraction device presented in this study is original and was made using dental materials employed on a daily basis.

The protocol proposed in this study produced substantial bone regeneration in the distraction gap, without the presence of dental or paradental tissues. In addition, the section orientation used in this study may prove useful to establish comparisons and perform histologic and static and dynamic histomorphometric studies, as well as immunohistochemical and other specific staining techniques, according to the particular aims of each study.

\section{Conclusion}

This model of mandibular rat distraction osteogenesis proved useful to obtain adequate quantity and quality of bone to study the bone regeneration process.

\section{Acknowledgements}

This work was supported by Grant UBACyT O 406. The authors want to express their gratitude to Ana Gomez, Mariela Lacave and Carolina Roman for their technical assistance.

4. McCarthy JG, Schereiber J, Karp N, Thorne CH, Grayson $\mathrm{BH}$. Lengthening the human mandible by gradual distraction. Plast Reconstr Surg. 1992 Jan;89(1):1-8.

5. Kesemenli CC, Subasi M, Kaya H, Sert C, Büyükbayram H, Arslan $\mathrm{H}$, et al. The effects of electromagnetic fields on distraction osteogenesis. Yonsei Med J. 2003 Jun 30;44(3):38591

6. Aronson J, Harrison B, Sewart C, Harp JH Jr. The histology of distraction osteogenesis using different external fixators. Clin Orthop Relat Res. 1989 Apr;(241):106-16. 
7. Aronson J, Shen XC, Skinner RA, Hogue WR, Badger TM, Lumpkin CK Jr. Rat model of distraction osteogenesis. J Orthop Res. 1997 Mar;15(2):221-6.

8. Mizuta H, Nakamura E, Mizumoto Y, Kudo S, Takagi K. Effect of distraction frequency on bone formation during bone lengthening. A study in chickens. Acta Orthop Scand. 2003 Dec;74(6):709-13.

9. Yasui N, Sato M, Ochi T, Kimura T, Kawahata H, Kitamura $\mathrm{Y}$, et al. Three modes of ossification during distraction osteogenesis in the rat. J Bone Joint Surg Br. 1997 Sep;79(5):824-30.

10. Djasim UM, Wolvius EB, van Neck JW, Weinans $H$, van der Wal KGH. Recommendations for optimal distraction protocols for various animal models on the basis of a systematic review of the literature. Int J Oral Maxillofac Surg. 2007 Oct;36(10):877-83.

11. Snyder CC, Levine GA, Swanson HM, Browne EZ. Mandibular lengthening by gradual distraction. Plast Reconstr Surg. 1973 May;51(5):506-8.

12. Troulis MJ, Glowacki J, Perrott DH, Kaban L. Effects of latency and rate on bone formation in a porcine mandibular distraction model. J Oral Maxillofac Surg. 2000 May;58(5):50714.

13. al Ruhaimi KA. A submerged osteodistraction device: an innovative technique for experimental animal studies. J Craniofac Surg. 2000 Jan;11(1):59-61.

14. Cheung LK, Zheng LW . Effect of recombinant human bone morphogenetic protein-2 on mandibular distraction at different rates in an experimental model. J Craniofac Surg. 2006;17(1):100-8.

15. Cheung LK, Zheng LW, Ma L. Effect of distraction rates on expression of bone morphogenetic proteins in rabbit mandibular distraction osteogenesis. J Craniomaxillofac Surg. 2006 Jul;34(5):263-9.

16. Rachmiel A, Potparic Z, Jackson IT, Sugihara T, Clayman L, Topf JS, et al. Midface advancement by gradual distraction. Br J Plast Surg. 1993 Apr;46(3):201-7.

17. Lewinson D, Maor G, Rozen N, Rabinovich I, Stahl S, Rachmeil A. Expression of vascular antigens by bone cells in a membranous bone distraction system. Histochem Cell Biol. 2001 Nov;116(5):381-8.

18. Khanal A, Yoshuioka I, Tominaga K, Furuta N, Habu M, Fukuda J. The BMP signaling and its Smads in mandibular distraction osteogenesis. Oral Dis. 2008 May;14(4):347-55.
19. Sasaki A, Sugiyama H, Tanaka E, Sugiyama M. Effects of sutural distraction osteogenesis applied to rat maxillary complex on craniofacial growth. J Oral Maxillofac Surg. 2002 Jun;60(6):667-75.

20. Rowe NM, Mehrara BJ, Babak J, Dudziak ME, Matthew E, Steinbrech DS, et al. Rat mandibular distraction osteogenesis: Part I. Histologic and radiographic analysis. Plast Reconstr Surg. 1998 Nov;102(6):2022-32.

21. Buchman SR, Ignelzi MA Jr, Radu C, Wilensky J, Rosenthal $\mathrm{AH}$, Tong L, et al. Unique rodent model of distraction osteogenesis of the mandible. Ann Plast Surg. 2002 Nov;49(5):5119.

22. Connolly JP, Liu Z, Wang L, Whelan MF, Huang GJ, Williams $\mathrm{JK}$, et al. A custom mandibular distraction device for the rat. J Craniofac Surg. 2002 May;13(3):445-50.

23. Eski M, Nisanci M, Cil Y, Sengezer M, Özcan A. A custommade distraction device for experimental mandibular distraction osteogenesis. J Craniofac Surg. 2005 Jul;16(4):675-83.

24. Kim UK, Chung IK, Lee KH, Swift JQ, Seong WJ, Ko CC. Bone regeneration in mandibular distraction osteogenesis combined with compression stimulation. J Oral Maxillofac Surg. 2006 Oct;64(10):1498-505.

25. Qi M, Hu J, Zou S, Zhou H, Han L. Mandibular distraction osteogenesis enhanced by bone marrow mesenchymal stem cells in rats. J Craniomaxillofac Surg. 2006 Jul;34(5):283-9.

26. Glowacki J, Schulten AJM, Perrott D, Kaban LB. Nicotine impairs distraction osteogenesis in the rat mandible. Int J Oral Maxillofac Surg. 2008 Feb;37(2):156-61.

27. Guglielmotti MB, Cabrini RL. Alveolar wound healing and ridge remodeling after tooth extraction in the rat: a histologic, radiographic and histometric study. J Oral Maxillofac Surg. 1985 May;43(5):359-64.

28. Ferreira de Albuquerque Jr R, Aparecida del Bel E, Brentegani LG, Moura de Oliveira MT, Mardegan Issa JP. Trigeminal nitric oxide synthase expression correlates with new bone formation during distraction osteogenesis. Calcif Tissue Int. 2008 Apr;82(4):309-15.

29. Ali MN, Eriji S, Kobayashi T, Anwar RB, Oda K, Ohshima $\mathrm{H}$, Saito C. Histologic study of the cellular events during rat mandibular distraction osteogenesis. Oral Surg Oral Med Oral Pathol Oral Radiol Endod. 2009 Mar;107(3):325-35.

30. Dixon RB, Tricker ND, Garetto LP. Bone turnover in elderly canine mandible and tibia [abstract]. J. Dent Res. 1997;76:2579. 